\title{
Standard Penetrasyon Testi (SPT) ile Afyonkarahisar Merkez Uydukent Bölgesi Zeminlerinin Sıvılaşma Potansiyelinin Araştırılması
}

\author{
${ }^{1}$ İsmail Zorluer and ${ }^{2}$ Süleyman Gücek \\ ${ }^{1,2}$ Faculty of Engineering, Department of Civil Engineering Kocatepe University, Turkey
}

\begin{abstract}
$\mathrm{Bu}$ çalışma, Afyonkarahisar il merkezinde 9 mahalleyi kapsayan Uydukent bölgesinin olası bir deprem etkisinde, yerleşim alanı içerisindeki alüvyal zeminlerin sıvılaşma potansiyelinin, arazi (SPT) verileri kullanılarak belirlenmesini içermektedir. $\mathrm{Bu}$ amaçla 70 noktada yapılan SPT verileri kullanılmıştır. Akşehir-Gediz Fay Sistemi, bölgeyi etkileyebileceği ve en büyük ivmeyi yaratabileceği varsayılarak, araştırmaya esas alınmıştır. Yeni deprem haritası üzerinden $0,4 \mathrm{~g}$ büyüklüğünde yatay deprem ivmesi oluşabileceği hesaplanmış ve SPT verileri kullanılarak sıvılaşma analizleri yapılmıştır. Analiz sonuçlarına göre çalışma sahasını temsilen, bölge genelinde orta ve yüksek dereceli sıvılaşma riski olasılıkları belirlenmiş ve buna göre sıvılaşma risk haritası ortaya konulmuştur.
\end{abstract}

Anahtar Kelimeler: SPT, Sıvılaşma Risk Haritası, Afyonkarahisar

\section{Giriş}

Kentsel mikrobölgeleme çalışmaları; bölgesel tehlike analizleri, yerel tehlike analizleri ve bölgeyi temsil edebilecek doğrulukta jeolojik, geoteknik ve jeofizik araştırmaları içerir. Bu tür araştırmalar karşılaşılabilecek olası doğal tehlikelerin kentsel yaşam alanlarımızdaki etki derecelerini ve etki biçimlerini belirlememizi sağlar.

Tanımlanmaya çalışılan problemin çözümü, birden fazla meslek disipliniyle ele alınabilmesi durumunda ancak mümkün olacaktır. Farklı meslek disiplinleri tarafindan ve birden çok yöntem kullanılarak elde edilen verilerin depolanması, coğrafi veri formatına dönüştürülmesi, kolay ulaşılabilir ve sorgulanabilir olması, analiz edilmesi ve yorumlanması ancak bilgi sistemi kullanılarak mümkün olabilir. Bu kapsamda coğrafi bilgi sistemi tekniklerinden yararlanılır. Ayrıca bu tür bilgi sistemleri, araziden toplanan coğrafi verilerin kullanıcı bağımlı olmadan değerlendirilmesi ve yorumlanmasına imkan tanır [1].

Depremler esnasında suya doygun zemin tabakalarında çevrimli yüklemeler altında oluşan boşluk suyu basıncı artışları zeminde katı fazdan sıvı faza dönüşme olarak nitelendirilebilecek sıvılaşma olayının ortaya çıkmasına neden olabilmektedir. Zeminlerin sıvılaşabilirliği tane boyutu ve dağılımı yanında, jeolojik yaşı ve çökelme koşulları, başlangıç sıkılık derecesine bağlı hacim değişim potansiyeli ve su geçirgenliği gibi özellikleri yanında depremin büyüklügüu, süresi uzaklığı gibi sismik faktörlere bağlıdır [2].

Depremler esnasında suya doygun zemin tabakalarında çevrimli yüklemeler altında oluşan boşluk suyu basıncı artışları zeminde katı fazdan sıvı faza dönüşme olarak nitelendirilebilecek sıvılaşma durumunun ortaya çıkmasına neden olabilmektedir. Zeminlerin sıvılaşabilirliği tane boyutu ve dağılımı yanında, jeolojik yaşı ve çökelme koşulları, başlangıç sıkılık derecesine bağlı hacim değişim potansiyeli ve su geçirgenliği gibi özellikleri yanında depremin büyüklüğü, süresi uzaklığı gibi sismik faktörlere bağlıdır [2]. Zemindeki yeraltı su seviyesinin 
yüzeye yakın olmasıyla birlikte zeminin gevşek şartlarda olması, zeminin sıvılaşması için etkili olan koşullardandır. Sıvılaşma olayı, pek çok depremde gelişmesine karşın ülkemizde, 1992 Erzincan depremiyle dikkate alınmaya başlanmış, 1999 Marmara depreminde meydana gelen sıvılaşma olayları ile bu olgunun önemi tüm kesimlerin ilgisini çekerek önem kazanmıştır. Afyonkarahisar merkezinde bulunan Uydukent bölgesinin zemininin jeolojik ve jeoteknik özelliklerini ortaya koymak ve olası bir depreme karşı dayanıklılığının tespitine yönelik yapılan çalışma kapsamında elde edilen SPT verileri kullanılmıştır. Bölgede alüvyal zeminlerin sıvılaşma riski değerlendirilmiştir.

$\mathrm{Bu}$ amaçla, bölgenin jeolojisinden, depremselliğinden, olası deprem odaklarının uzaklığı ile oluşturacakları yer ivmesi ilişkilerinden, zemine ait granülometri değerlerinden ve SPT verilerinden yararlanılarak SPT'ye ve Kıvam Limitlerine göre sıvılaşma analizleri yapılmış ve sıvılaşma potansiyeli araştırılmıştır. Afyonkarahisar Uydukent bölgesi yerleşim yerinde jeolojik, geoteknik, jeofizik araştırmalar ve yapı envanter bilgilerinin toplanmasına yönelik çalışmalar yapılmış, toplanan veriler coğrafi veri formatında değerlendirilerek kentsel mikrobölgeleme haritaları üretilmiştir

\section{Materyal ve Metot}

\subsection{Materyal}

\subsection{1. Çalışma alanının tanımlanması}

İnceleme alanı; Afyonkarahisar ili, Merkez ilçesinde 9 mahallenin bulunduğu Uydukent bölgesidir. İnceleme alanında eğim yoktur. İnceleme alanında, gözlemsel olarak yapılan değerlendirmeler ve İmar Planına Esas Jeolojik Etüt Raporuna göre; morfolojik ve jeolojik açıdan inşaat yapımına engel bir sorun olmayıp, heyelan, kaya düşmesi, sel, çökme, vb, gibi afet oluşturacak unsurlar bulunmamaktadır. Yağış sularının kolayca bölgeyi terk edebilmesi amacıyla bölge merkezinde bulunan Akarçay kanalına gerekli drenaj ağları oluşturulmuştur. İl merkezinde karasal iklim hüküm sürmektedir. Yaz mevsimi sıcak ve kurak, kış mevsimi soğuk ve yağışlı olmaktadır.

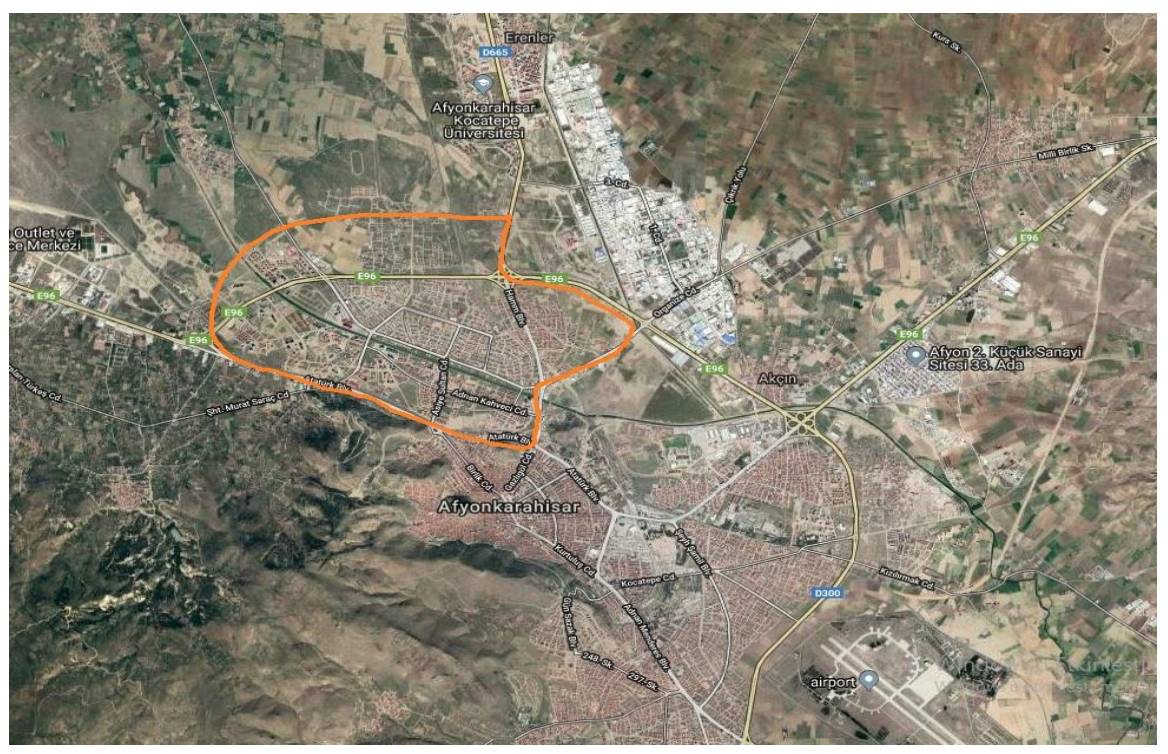

Şekil 1. Afyonkarahisar Merkez Çalışma Bölgesi 


\subsubsection{Inceleme alanının jeolojisi}

Afyon ve çevresini içine alan bölgede farklı litolojik ve tektonik özelliklere sahip kuşlaklar yer almaktadır. Bunlar Toros ve İç Toros tektonik kuşlaklardır. Afyon ve dolayında birbirinden tektonik dokanakla ayrılmış iki temel kaya topluluğu mevcuttur. Bunlardan birisi Toros Kuşağına ait Sultan Dağları'nın devamını oluşturan Toros Paleozoik ve Mesozoyik birimleridir.Diğeri ise İç Toros Kuşağında yer alan ve Afyon'un $\mathrm{KD}, \mathrm{K}, \mathrm{KB}$ ve B'sında Neojen Örtüsü altında geniş alanlar kaplayan "Afyon Metamorfikleri”dir. Diğer yandan Sandıklı'nın kuzey kesiminde, altta “Afyon Metamorfitleri” üzerine transgressif bir konglomera ile Afyon ve çevresindeki diğer benzerlerinden tamamen farklıdır [3].

\subsubsection{Inceleme Alanının Mühendislik Jeolojisi}

İnşa yapılacak alan, üstte alüvyon örtü olarak adlandırdığımız, kuvaterner yaşlı detritik, kohezyonsuz birimlerden oluşmuştur. İnce çakıl, kum, silt ve kilin karmaşık derecelenmesinden oluşan alüvyonun kalınlığı, yaklaşık 130 mt. kadardır. Alüvyonda kil ve siltin oranı daha fazladır. Kil, düşük plastisiteli inorganik'tir. İnce çakıl, trakit orijinlidir. Alüvyonun porozite ve permeablitesi yüksektir [3].

\subsubsection{Zemin Profilinin Yorumlanmast}

İnceleme alanının oluşturan birim Kuvaterner yaşlı yumuşak kıvamda, gri renkli, siltli ve çakıllı kumlardan oluşan Alüvyon formasyonudur. Temel taban kodu olarak binanın bodrumlu olduğu da göz ününe alınarak yaklaşık $1.50 \mathrm{~m}$ den sonrası düşünülebilir. Söz konusu parsel civarında açılan sondaj kuyularında statik su seviyesi yaklaşık $6,00 \mathrm{~m}$. civarındadır. Ancak yağışlardan dolayı suyun süzütüp temele etki etmemesi için gerekli önlemlerin alınması faydalı olacaktır.

\subsubsection{Doğal Afet Risklerinin Dĕgerlendirilmesi}

Afyonkarahisar ili ve çevresi, yakın tektonik sistemlerin yönlendirdiği deprem rejimine göre, bugüne kadar en az 4,0 büyüklükte ( $M>4) 252$ deprem yaşandı. Batı Anadolu'da etkin olan Gediz Graben sistemi, Dinar fay sistemi ile Afyonkarahisar'ın güneydoğusundan kuzeybatısına doğru uzanan Akşehir fay sistemi ve Emirdağ fay sistemlerinin etkisinde kalan Afyonkarahisar ili ve civarı 5 ayda bir en az 4,0 büyüklüğünde bir deprem üreten aktif bir tektonik sistemin içerisinde yer almaktadır [4].

Bu özeliği ile 6,0 büyüklüğündeki bir depremi 30 yılda bir \%78, 7,0 büyüklügündeki bir depremi ise aynı sürede \% 35 yaşama olasılığı vardır. Kayıtlara göre bu bölgede yaşanan en büyük deprem 1931 yılında 7,0 büyüklüğündedir. Günümüze kadar en az 6,0 büyüklüğünde 8 depremin meydana geldiği Afyonkarahisar ili ve çevresi ikinci derece deprem bölgesi olarak tanımlanır [4].

Afyonkarahisar ili merkezi civarındaki küçük faylar dikkate alınmazsa, yapılaşma alanına aktivitesi kesin olarak bilinen en yakın fay (03.02.2003 Çay Depremi) Sultandağ 1 fayıdır. Bu fayın inceleme alanına olan mesafesi yaklaşık $35 \mathrm{~km}$ civarındadır. Yine yakın zamanda 
deprem üreten diğer fay ise Eğirdir Gölü içinden geçen Kumdanlı Fayı ile Tatarlı Fayıdır(1995 Dinar Depremi) Bölge açısından bu fayında inceleme alanına olan uzaklığı yaklaşık 50- $60 \mathrm{~km}$ civarındadır [4].

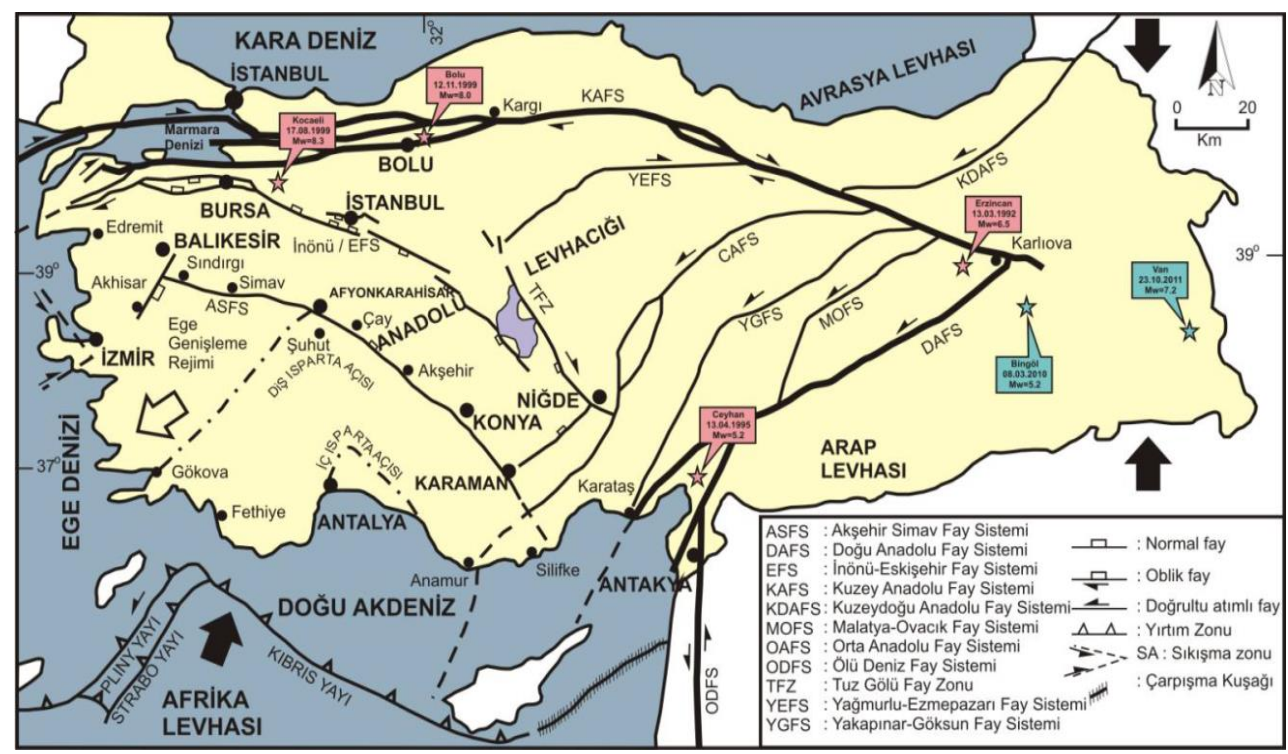

Şekil 2. Türkiye ve yakın çevresinin yalınlaştırılmış tektonik haritası

\subsubsection{Kayıt Verileri}

İnceleme alanının da içinde bulunduğu yerleşim birimi olan Afyonkarahisar il merkezi ele alındığında Türkiye Deprem Bölgeleri Haritası, AFAD Deprem Dairesi Başkanlığı tarafindan 1 Ocak 2019 tarihinde yürürlüğe giren deprem haritasına göre en büyük yer ivmesi (g) 0.4 olarak güncellenmiştir.

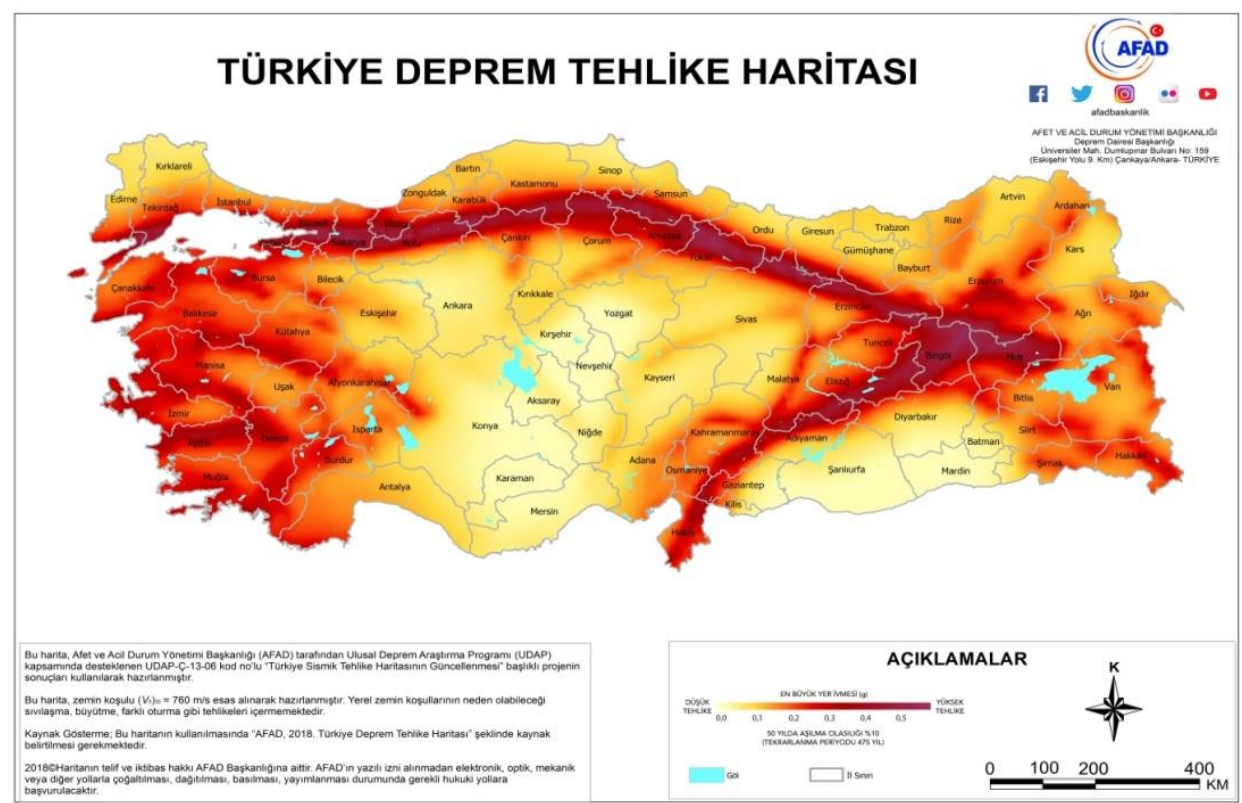

Şekil 3. Türkiye Deprem Tehlike Haritası (2019) 


\subsubsection{Arazi verileri}

Çalışmada, geleneksel sıvılaşma potansiyeli hesaplamalarının yapılması için, derinlikleri en az $15 \mathrm{mt}$. olan 70 adet zemin sondajının SPT (Standard Penetrasyon Test) verileri kullanılmıştır [4]. Bu sondaj raporu verileri özel yapı denetim firmalarından alınmıştır.

Zemin sondajları; ilerlemeye paralel olarak, her $1.50 \mathrm{~m}$ de SPT deneyi yapılmış ve örselenmiş örnekler alınarak elde edilmiştir. Çalışma alanından elde edilen parametreler kullanılarak mühendislik değerlendirmesi ve analizleri yapılmıştır.

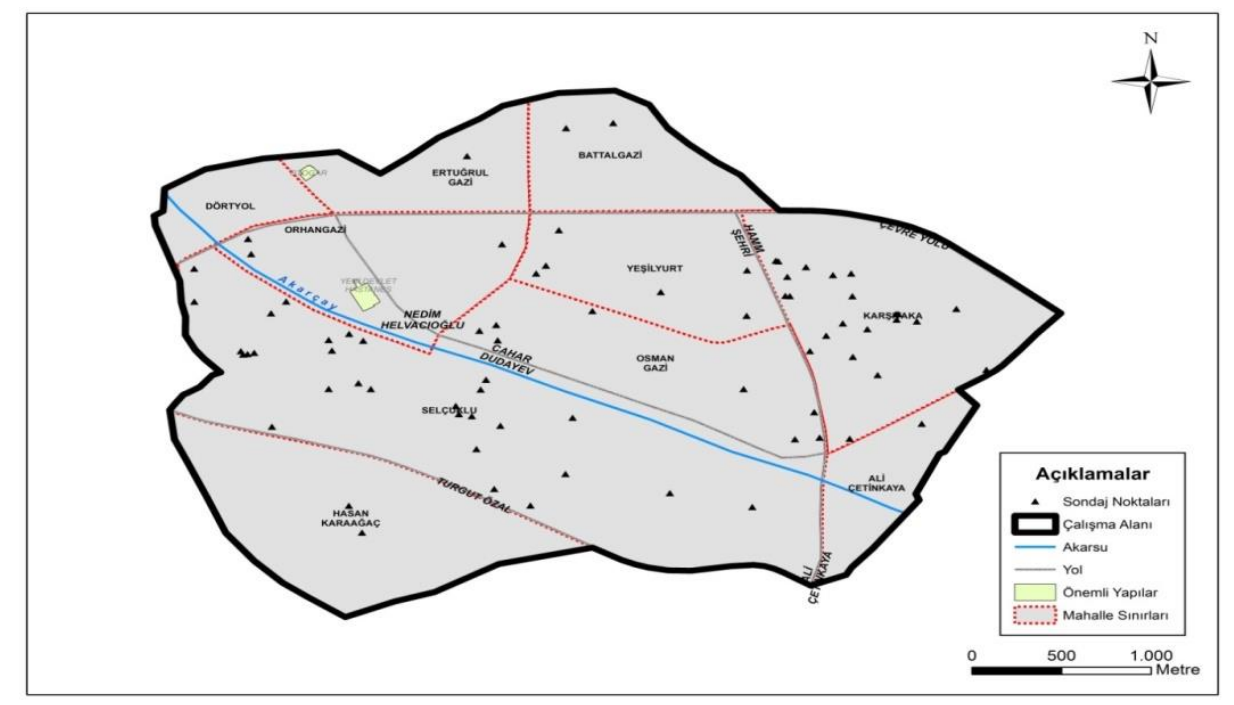

Şekil 4. Çalışma Bölgesi Sondaj Noktaları Dağılımı

\subsubsection{Yer altı suyu durumu}

Sıvılaşma potansiyeli olan bölgeleri belirlemede, dikkat edilmesi gereken önemli parametrelerden birisi de, yer altı suyunun yüzeyden itibaren derinliğidir. Çalışma alanında yer altı suyu, durumuna gelince, yeraltı suyu yaz ve kış aylarında mevsimsel olarak değişmektedir. Sondaj raporları sonuçlarına göre bölgenin yer altı su seviyesi yaz aylarında yaklaşık $6 \mathrm{mt}$. olup, kışın ise $4.5 \mathrm{mt}$. seviyesine kadar yükselmektedir.

\subsubsection{Deneyde kullantlan yazılımlar}

Bu çalışmada, Arazi verilerinin sıvılaşma potansiyel hesaplamalarında, HS Jeotek ve Liq IT V.4.7.3 yazılımı kullanılmıştır. 


\subsection{Metot}

$\mathrm{Bu}$ çalışma kapsamında çalışma alanından elde edilen SPT verileri esas alınarak, orijinal olarak Seed ve Idriss [5] tarafından geliştirilen ve daha sonra Youd vd. [6] tarafindan revize edilen sıvılaşma analiz yöntemine göre HS Jeotek ve LiqIT [7] Geologismiki yazılımı kullanılarak sıvılaşma analizleri yapılmıştır.

Deprem anında meydana gelen sıvılaşma, üst yapıda büyük hasarlara neden olabilecek bir zemin problemidir. Sıvılaşma kaynaklı hasarı minimuma indirgemek için, sıvılaşmanın olabileceği yerler önceden belirlenip zemin iyileştirme metotlarının uygulanması gerekmektedir Afyonkarahisar Uydukent bölgesi çalışma alanında sıvılaşma potansiyelinin belirlenmesi amacıyla 70 ayrı noktadaki SPT sonuçları dikkate alınmıştır. Ayrıca yapılan sondaj çalışmaları ile alınan zemin numunelerinin fiziksel özellikleri özel sektördeki laboratuvarlarda yapılan deneyler sonucunda belirlenmiştir. Sıvılaşma potansiyelinin belirlenmesinde SPT deney verileri ile yapılan hesaplamalarda Seed and Idriss tarafindan önerilen eşitlik kullanılmıştır.

Ancak sıvılaşma potansiyelinin belirlenmesinde güvenlik katsayısının (FS) literatürde yapılan çalışmalar neticesinde tek başına yeterli olmadığı görülmüş ve bunun için sıvılaşma risk indeksi (Ls) parametresi belirlenerek bölgenin sıvılaşma risk haritası hazırlanmıştır. Sıvılaşma risk indeksi, $M w=6,0$ olan senaryo bir deprem büyüklüğüne göre belirlenmiş ve sonuçlar hazırlanan harita üzerinde gösterilmiştir.

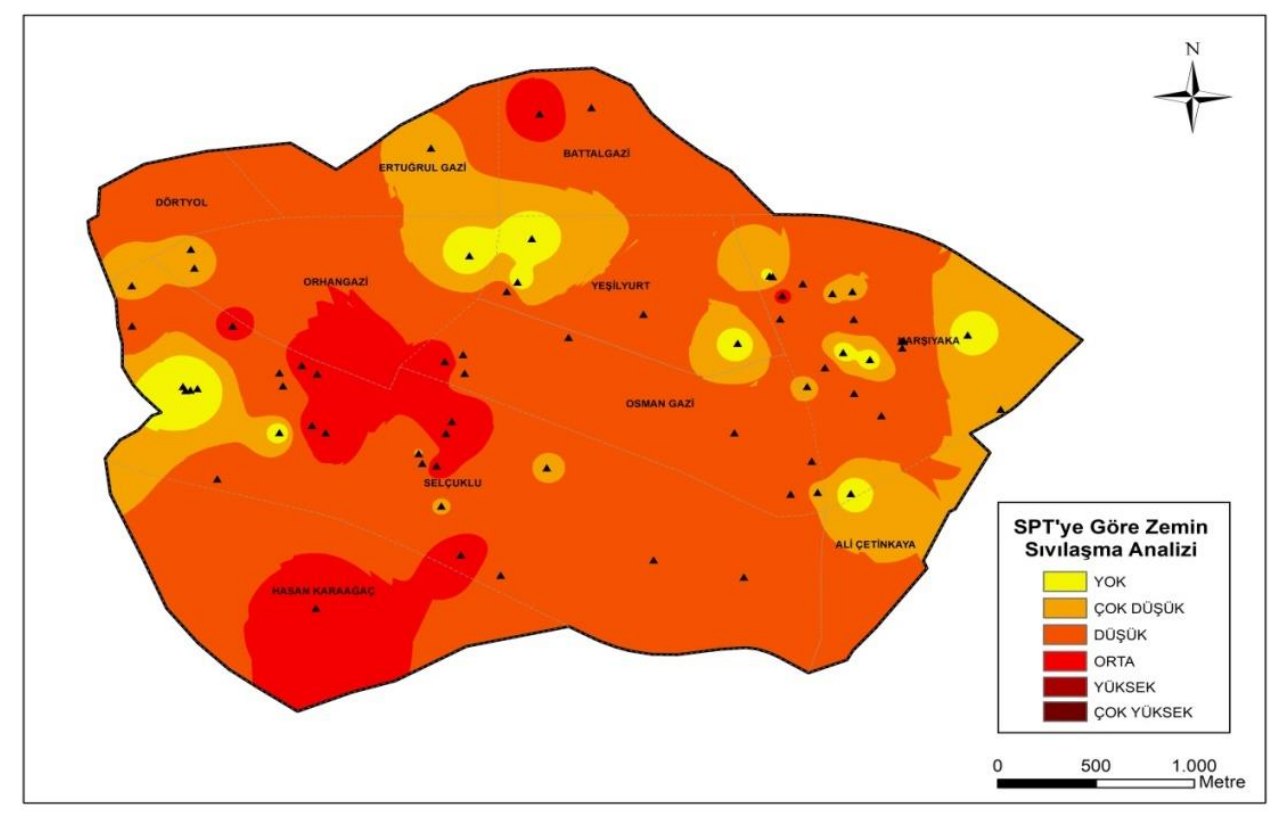

Şekil 5. Çalışma Bölgesinin Sıvılaşma Haritası 


\section{SONUÇLAR}

$\mathrm{Bu}$ çalışmada, imara açılmış olan ve sıvılaşma potansiyeli taşıyan alandaki standard penetrasyon testi (SPT) verileri ile deprem kaynağı olarak Akşehir Simav Fay Sistemi (ASFS) tepit edilmiş ve bu fay zonunun üretmesi beklenen tasarım parametreleri; "maksimum yatay deprem ivmesi $0,4 \mathrm{~g}$ ve moment magnitüdü 6", olarak hesaplanmış olup bu parametrelere göre sıvılaşma analizi yapılmıştır. Analizler sonucu, Bölgede orta ve yüksek sıvılaşma potansiyeli gösterebilen noktalar belirlenmiştir (Şekil 5).

Sıvılaşma analizi için yapılan hesaplamaların kullanılabilmesi için, yönetmeliklerde ve literatürde de belirtildiği üzere sondaj kaya zemine ulaşmıyorsa en az $20 \mathrm{~m}$ derinlik için yapılması gerekmektedir. Haritaya göre bazı bölgelerde sıvılaşmaya karşı zemin iyileştirmesi gerekliliği ortaya çıkmaktadır.

\section{KAYNAKLAR}

[1] M. Tün, U. Avdan, Y. Güney, Kentsel Mikrobölgeleme Çalışmalarında Coğrafi Bilgi Sistemi Tekniklerinden Yararlanılması, III. Uzaktan Algılama Ve Coğrafi Bilgi Sistemleri Sempozyumu, 11 - 13 Ekim 2010, Kocaeli.

[2] Özaydın K, Zeminlerde Sıvılaşma. Altıncı Ulusal Deprem Mühendisliği Konferansı, İstanbul, 2007, 231-255.

[3] Metin, S., Genç, Ş. Ve Bulut, V., (1987), Afyon Ve Yakın Dolayının Jeolojisi, M.T.A. Rap. No: 8103, Ankara.

[4] Ali Koçyiğit, Güney Batı Türkiye Ve Yakın Dolaylarında Levha İçi Yeni Tektonik Gelişimi, 1984.

[5] Seed H.B, Idriss I.M. Simplified Procedure For Evaluating Soil Liquefaction Potential. Journal Of Geotechnical Engineering, Asce, 1971, 97(9), 1249-1273.

[6] Youd T.L Et Al. Liquefaction Resistance Of Soils: Summary Report From The 1996 NCEER And 1998 NCEER/NSF Workshops On Evaluation Of Liquefaction Resistance Of Soils. Journal Of Geotechnical And Geoenvironmental Engineering, Asce, 2001, Vol.127, No.10, Pp.817-832.

[7] İnternet: Liqı1 4.7.3 Geologismiki (2006), Sıvılaşma Analizi Yazılımı" www.geologismiki.gr (2006). 